03.1;03.4;05.1

\title{
Анализ суперкаверн, формируемых при высокоскоростном движении в воде группой ударников
}

\author{
(ㄱ А.Н. Ищенко, В.В. Буркин, А.С. Дьячковский , А.В. Чупашев, А.Ю. Саммель, К.С. Рогаев, А.Д. Сидоров \\ Научно-исследовательский институт прикладной математики и механики Национального исследовательского Томского \\ государственного университета, Томск, Россия \\ ฯE-mail: Lex_okha@mail.ru
}

Поступило в Редакцию 27 июля 2021 г.

В окончательной редакции 14 сентября 2021 г.

Принято к публикации 14 сентября 2021 г.

Выполнен анализ суперкаверн, формирующихся при высокоскоростном движении в воде двух близкорасположенных суперкавитирующих ударников. На основе сравнения геометрических характеристик суперкаверн показаны возможности проведения качественной оценки степени влияния близкорасположенных ударников друг на друга. Определено характерное расстояние между двумя ударниками, при достижении которого наблюдается минимальное взаимовлияние ударников друг на друга.

Ключевые слова: суперкаверна, групповое метание, размеры каверн, высокоскоростная съемка, взаимное влияние.

DOI: 10.21883/PJTF.2022.01.51870.18978

Исследуется высокоскоростное движение в воде нескольких одновременно стартующих близкорасположенных суперкавитирующих ударников. При входе в воду группы удлиненных осесимметричных ударников на расстоянии нескольких диаметров кавитатора (до 10-20 диаметров) на траектории движения наблюдается их активное взаимное влияние друг на друга. Ударники при движении расходятся относительно друг друга. Предварительный анализ этого взаимовлияния, проведенный в [1], показал, что на отклонение траекторий от оси прицеливания значительное влияние оказывают массы ударников.

В настоящей работе основное внимание уделяется анализу суперкаверн [2-4], формируемых двумя одновременно стартующими близкорасположенными ударниками. Сравнение геометрических параметров каверн на нескольких участках их движения позволяет на качественном уровне оценить степень взаимовлияния ударников в зависимости от их положения относительно друг друга. Каверны сравнивались путем наложения контуров их профилей. Для более точного исследования изменения параметров каверн, полученных при групповом движении ударников, для сравнения привлекались каверны, полученные при движении в воде таких же по форме одиночных ударников.

В экспериментах использовались конические ударники сложной формы с удлинением $12 \mathrm{~mm}$ и кавитаторами диаметром $1.2-1.3 \mathrm{~mm}$, изготовленные из сплава ВНЖ. Ударники располагались в вертикальной плоскости друг над другом на расстоянии $12 \mathrm{~mm}$ между их осями. Ударники, выполненные из сплава ВНЖ, имели масcy 34 g. Диапазон скоростей ударников при входе в воду составлял $400-500 \mathrm{~m} / \mathrm{s}$.

Формирование суперкаверн при высокоскоростном движении в воде исследовалось на гидробаллистической трассе с применением высокоскоростной съемки [5].
На рис. 1 приведены типичные фотографии движения одиночного ударника $(a)$ и двух одновременно стартующих ударников $(b)$ и формирующихся при их движении каверн. На вставках к рис. 1 показаны типичные метаемые сборки с ведущими устройствами.

На рис. 2, a показана фотография движения со скоростью входа в воду $480 \mathrm{~m} / \mathrm{s}$ двух ударников, изготовленных из сплава ВНЖ. На расстоянии $0.7 \mathrm{~m}$ от входа в воду их скорость составила $470 \mathrm{~m} / \mathrm{s}$, а расстояние между ними - $12 \mathrm{~mm}$. На рис. 2, $b$ приведены соответствующие контуры профилей сравниваемых каверн. Для сравнения приведен контур каверны, полученной при движении со скоростью $489 \mathrm{~m} / \mathrm{s}$ одиночного ударника с таким же диаметром кавитатора.

Видно, что для верхнего ударника значительно изменяется форма нижней части профиля 3 по сравнению с профилем каверны, полученным при движении одиночного ударника. Нижняя граница каверны прижимается
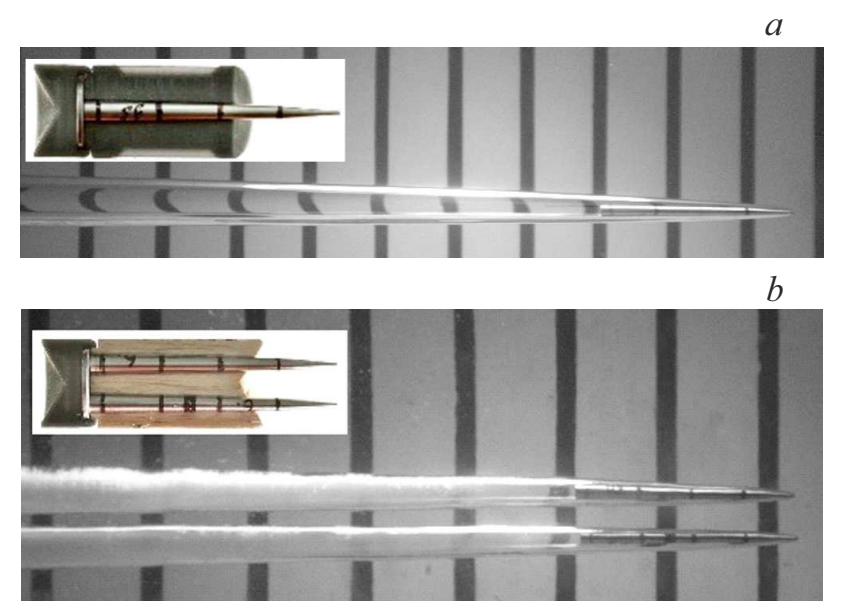

Рис. 1. Фотографии движения в воде одиночного ударника (a) и двух одновременно стартующих ударников $(b)$. 
к кормовой части ударника. Для нижнего ударника, наоборот, заметные изменения претерпевает верхний профиль каверны 2 по сравнению с профилем каверны, полученным при движении одиночного ударника, и уже верхняя граница каверны прижимается к кормовой части ударника. Полученные искажения каверн могут быть вызваны повышенным давлением в области между ударниками. Искажения каверн в виде сближения с кормовой
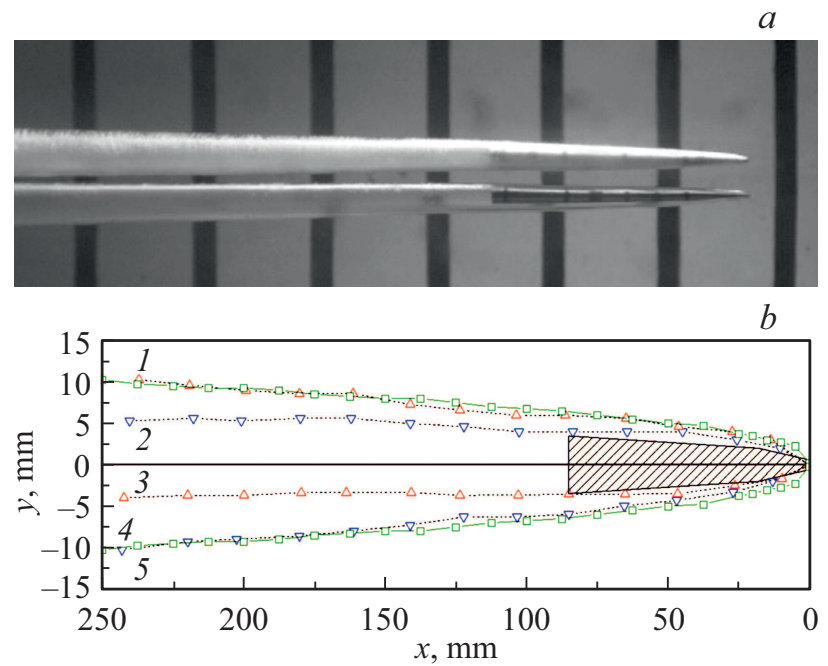

Рис. 2. $a-$ - фотография движения со скоростью $470 \mathrm{~m} / \mathrm{s}$ двух суперкавитирующих ударников. $b-$ контуры профилей каверн, формируемых ударниками, находящимися на расстоянии $12 \mathrm{~mm}$ друг от друга. 1,3 - соответственно верхний и нижний контуры суперкаверны верхнего ударника; 2, 4 - соответственно верхний и нижний контуры суперкаверны нижнего ударника; 5 - контур суперкаверны одиночного ударника.
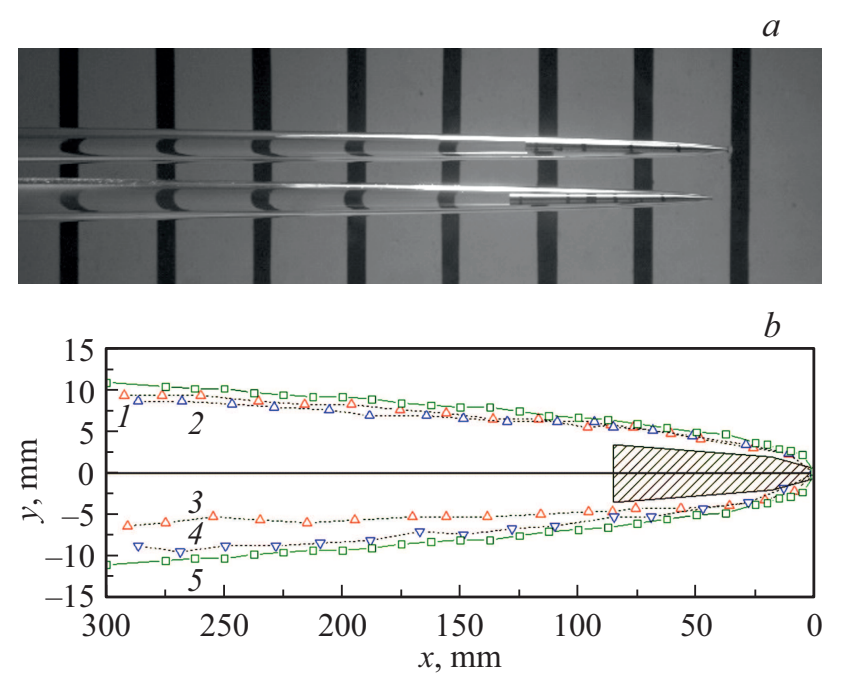

Pис. 3. $a-$ фотография движения со скоростью $450 \mathrm{~m} / \mathrm{s}$ двух суперкавитирующих ударников. $b-$ контуры профилей каверн, формируемых ударниками, находящимися на расстоянии $24 \mathrm{~mm}$ друг от друга. $1,3-$ соответственно верхний и нижний контуры суперкаверны верхнего ударника; 2, 4 соответственно верхний и нижний контуры суперкаверны нижнего ударника; 5 - контур границ суперкаверны одиночного ударника. частью ударников могут привести к раннему „замыву“ ударников и прекращению суперкавитирующего режима их движения.

На рис. 3 представлены фотография и контуры профилей каверн, полученных в том же эксперименте, на траектории их движения, когда расстояние между расходящимися ударниками составило $24 \mathrm{~mm}$. Там же для сравнения приведен контур каверны, образованный одиночным ударником. Видно, что радиальный размер каверны от одиночного ударника немного больше, что обусловлено более высокой скоростью его движения $(489 \mathrm{~m} / \mathrm{s})$.

Сравнение профилей верхней и нижней каверн 1 и 2 показывает, что профили каверн при достижении расстояния между ударниками $24 \mathrm{~mm}$ практически совпадают. Это означает, что силовое воздействие на каверны, а следовательно, и взаимовлияние между ударниками значительно снижаются при данном расстоянии между ударниками.

Выполненный анализ контуров формируемых каверн показал, что с увеличением расстояния между ударниками с диаметром кавитатора $1.2-1.3 \mathrm{~mm}$, стартующими в группе, их взаимовлияние друг на друга снижается и на расстоянии около $30 \mathrm{~mm}$ практически полностью исчезает. Предложенный способ качественной оценки степени взаимовлияния ударников друг на друга может применяться в анализе подводного группового движения с большим количеством одновременно стартующих ударников.

\section{Финансирование работы}

Исследование выполнено за счет гранта Российского научного фонда (проект № 19-19-00233).

\section{Конфликт интересов}

Авторы заявляют, что у них нет конфликта интересов.

\section{Список литературы}

[1] А.Н. Ищенко, С.А. Афанасьева, В.В. Буркин, А.С. Дьячковский, А.В. Чупашев, Письма в ЖТФ, 45 (20), 47 (2019). DOI: 10.21883/PJTF.2019.20.48395.17950 [A.N. Ishchenko, S.A. Afanas'eva, V.V. Burkin, A.S. D'yachkovskii, A.V. Chupashev, Tech. Phys. Lett., 45 (10), 1059 (2019). DOI: 10.1134/S1063785019100225].

[2] С.В. Федоров, В.А. Велданов, ЖТФ, $\mathbf{8 3}$ (2), 15 (2013). https://journals.ioffe.ru/articles/10815 [S.V. Fedorov, V.A. Veldanov, Tech. Phys., 58, (2), 165 (2013). DOI: $10.1134 / \mathrm{S} 1063784213020072]$

[3] I. Kirschner, in Agard-R-827 (1998). p. 35. https://www.sto.nato.int/publications/AGARD/AGARD-R-827/ AGARD-R-827.pdf

[4] Ю.Н. Савченко, Прикладная гидромеханика, 9 (2-3), 150 (2007).

[5] А.Н. Ищенко, Р.Н. Акиншин, С.А. Афанасьева, И.Л. Борисенков, Н.Н. Белов, В.В. Буркин, А.С. Дьячковский, Л.В. Корольков, М.В. Хабибуллин, А.В. Чупашев, Н.Т. Югов, в сб. Фундаментальная наука - военно-морскому флоту. Материаль круглого стола в рамках VIII Межсдународного военно-морского салона (Изд-во НИИ „Центрпрограммсистем“, Тверь, 2018), т. 3, с. 120. 